\title{
A putative N-BAR-domain protein is crucially required for the development of hyphae tip appressorium-like structure and its plant infection in Magnaporthe oryzae
}

\author{
Lili Lin ${ }^{1 \dagger}$, Xiaomin Chen ${ }^{1 \dagger}$, Ammarah Shabbir ${ }^{1}$, Si Chen ${ }^{1}$, Xuewen Chen ${ }^{1}$, Zonghua Wang ${ }^{1,2^{*}}$ and
} Justice Norvienyeku ${ }^{1 *}$ (D)

\begin{abstract}
Membrane remodeling modulates many biological processes. The binding of peripheral proteins to lipid membranes results in membrane invaginations and protrusions, which regulate essential intra-cellular membrane and extra-cellular trafficking events. Proteins that bind and re-shape bio-membranes have been identified and extensively investigated. The Bin/Amphiphysin/Rvs (BAR) domain proteins are crescent-shape and play a conserved role in tubulation and sculpturing of cell membranes. We deployed targeted gene replacement technique to functionally characterize two hypothetical proteins (MoBar-A and MoBar-B) containing unitary N-BAR domain in Magnaporthe oryzae. The results obtained from phenotypic examinations showed that MoBAR-A deletion exerted a significant reduction in the growth of the defective $\triangle$ Mobar-A strain. Also, MoBAR-A disruption exclusively compromised hyphae-mediated infection. Additionally, the targeted replacement of MOBAR-A suppressed the expression of genes associated with the formation of hyphae tip appressorium-like structure in $M$. oryzae. Furthermore, single as well as combined deletion of MoBAR-A and MOBAR-B down-regulated the expression of nine different membrane-associated genes. From these results, we inferred that MOBAR-A plays a key and unique role in the pathogenesis of $M$. oryzae through direct or indirect regulation of the development of appressorium-like structures developed by hyphae tip. Taken together, these results provide unique insights into the direct contribution of the N-BAR domain proteins to morphological, reproduction, and infectious development of $M$. oryzae.
\end{abstract}

Keywords: Magnaporthe oryzae, Peripheral membrane protein, Appressorium-like structure, N-BAR domain, Membrane tubulation

\section{Background}

Vesicle trafficking is an essential cellular process that facilitates the transport of proteins and other secreted molecules internally between different cellular compartments or externally with their environment (Richter et al. 2014; Sun 2015). Vesicle trafficking modulates the operations of major transport systems, including retrograde transport, trans-Golgi transport network, and the vacuolar transport systems (Williams and Kim 2014;

\footnotetext{
* Correspondence: wangzh@fafu.edu.cn; jk_norvienyeku@fafu.edu.cn

${ }^{\dagger}$ Lili Lin and Xiaomin Chen contributed equally to this research.

${ }^{1}$ State Key Laboratory for Ecological Pest Control of Fujian and Taiwan Crops, College of Life Science, Fujian Agriculture and Forestry University, Fuzhou 350002, China

Full list of author information is available at the end of the article
}

McDermott and Kim 2015). Endocytosis and exocytosis are some of the essential transport pathways that facilitate the movement of vesicles, cargoes, and other molecules in and out of the cell.

Studies have shown that the efficiency of cellular transport machinery depends on the organization of components of the cytoskeleton system in tandem with membrane dynamics (Flynn 2013; Grassart et al. 2014; Carlier et al. 2015). Moreover, during cargo selection processes, the cargo receptors on the donor membrane bind to the signal peptide sequences of the secreted proteins or cargoes sorted from the donor compartment for export. The adaptor proteins subsequently bind to cargo receptors from the cytoplasmic side of the donor 
membrane to initiate the filtering and attachment of cargoes to receptors. The cargo receptors also serve as interphase for coat formation (Chi et al. 2015; GomezNavarro and Miller 2016). These coat proteins, in turn, bind the adaptor proteins attached to the cargo receptors containing the cargo proteins. Interactions between coat protein and cargo-receptor complex eventually trigger scaffolding and result in the bending of the plasma membrane to produce membrane curvatures required for budding (Gomez-Navarro and Miller 2016). Membrane sculpturing and membrane tubulation facilitate the establishment of the biological platform needed to accelerate the operations of different cellular transport machinery, including endocytosis and exocytosis.

However, membrane sculpturing and membrane tubulation would not have been possible without the coordinated actions of BAR domain-containing proteins (Mim and Unger 2012; Meinecke et al. 2013; Simunovic et al. 2015; Suetsugu 2016). Currently, more than 220 BAR domain-containing proteins are present in different organisms across kingdoms and are categorized into three major families on the basis of their structural and phylogenetic characteristics, including (Fes/CIP4homology BAR) F-BAR domain family, N-terminal amphipathic helix domain family (N-BAR-domain) and the inverse BAR domain family (I-BAR-domain).

Structurally, the BAR-domain refers to a bananashaped structure with a crescent-shaped surface covered with a mass of positively charged residues enabling it to interact directly with negatively charged membrane lipids including phosphoinositides, phosphatidylserine or phospholipids (Noguchi 2016; Suetsugu 2016). These structural properties enable BAR domain-containing proteins to promote membrane tubulation readily. The inherent crescent-shaped structure of the BAR domain dimers makes them ideal cellular tools for sensing and inducing membrane curvature (Salzer et al. 2017).

Previous studies have identified actin-mediated regulation of endocytosis as a fundamental pre-requisite for controlling extra-cellular signaling activities required to shape morphogen gradients and to orchestrate cell fate decisions within defined tissues (Baluška and Levin 2016; Soykan et al. 2017). BAR-domain containing proteins support the progression of endocytosis by mediating the coupling of membrane curvature and actin dynamics to ensure successful harnessing of actin generated force required to drive membrane invagination, constrict neck of nascent vesicles, support vesicle scission and also to propel vesicles away from the plasma membrane (Lanzetti 2007; Paez Valencia et al. 2016).

Although mounting evidences suggest that membrane curvature mediated by BAR-domain containing proteins play crucial roles in regulating various cellular processes such as vesicle trafficking, endocytosis, phagocytosis, adhesion, cell division/differentiation and tubule formation, recruiting Wiskott Aldrich Syndrome protein (WASP) family, and activating the Arp $2 / 3$ complex required for inducing the nucleation of new actin filaments (Saarikangas et al. 2010), there is currently no record on the role of BAR-domain containing proteins in the economically destructive rice blast pathogen $M$. oryzae. In this study, we identified and evaluated the physiological and biological functions of two putative BAR-domain containing proteins (MoBar-A and MoBarB) in M. oryzae.

\section{Results}

Gene identification and phylogeny of $M$. oryzae specific BAR-domain containing proteins

To identify BAR-domain containing proteins in $M$. ory$z a e$. The amino acids (aa) sequences of BAR-domain containing proteins from Aspergillus nidulans, Botrytis cinerea, Sclerotinia sclerotiorum, Fusarium graminearum, Fusarium verticillioides, and Neurospora crassa were used to run BLASTP and Reverse BLASTP-Search in the publicly accessible fungal and oomycete genomic resource database (http://fungidb.org/fungidb/) and in the $M$. oryzae genomes data unit of the highly versatile Kyoto Encyclopedia of Genes and Genomes (KEGG) (http://www.kegg.jp/kegg-bin/show_organism?org=mgr). Two putative BAR-domain containing genes, MoBAR-A and $M o B A R-B$, in the genome of the rice blast fungus were identified. To confirm that the respective sequences obtained from the various organisms contained the BAR-domain, we used Pfam-domain search resource (http://pfam.xfam.org/search/sequence) to conduct domain confirmation and meanwhile to construct domain architecture. It was revealed that MoBar-A contained a $\mathrm{N}$-terminal BAR (N-BAR) domain, while MoBar-B possessed a BAR_2 domain (Fig. 1a). Additional results obtained from the phylogenetic analysis showed that MoBar-A and MoBar-B are phylogenetically diverse from each other. We observed that MoBar-A shared a recent evolutionary history with BAR-domain containing proteins from Scedosporium apiospermum, Lomentospora prolificans and a high domain sequence homology with that from Sporothrix brasiliensis while MoBar-B formed a separate clade and shared a high domain sequence homology with those from Sporothrix schenckii and S. sclerotiorum (Fig. 1b, c, Additional file 1: Figure S1 and Table S1). From these observations, we deduced that this two BAR-domain containing proteins likely play distinct functions.

Localization of MoBar-A and MoBar-B and the expression level of their respective genes during $M$. oryzae infection We investigated the subcellular localization of MoBar-A and MoBar-B by transforming green fluorescent protein 


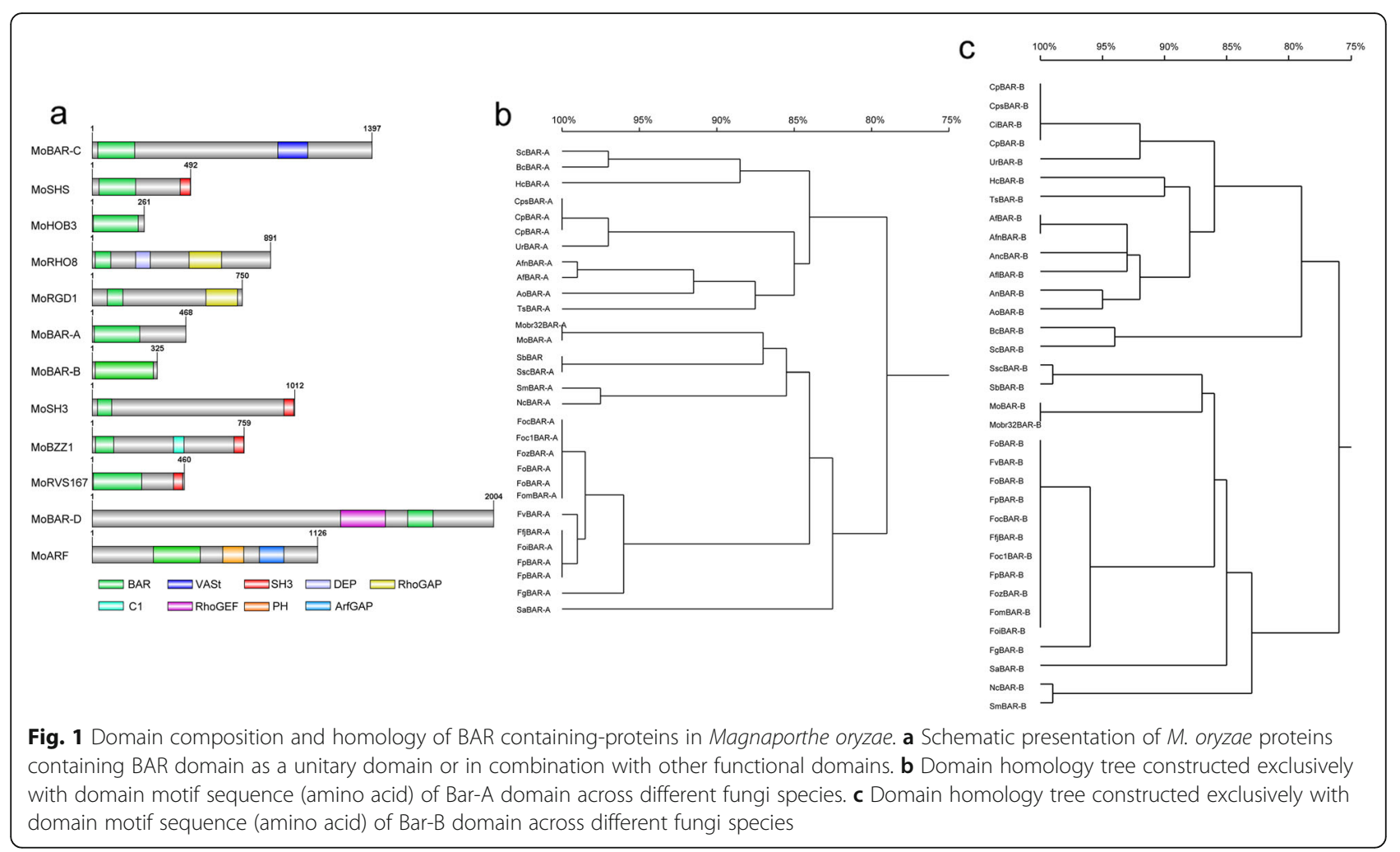

(GFP) fusing constructs of MoBar-A (GFP-MoBar-A) and MoBar-B (MoBar-B-GFP) under their respective native promoters into the protoplasts of the Guy11 strain. Results obtained from microscopy examination of individual strains harboring the GFP-MoBar-A and MoBarB-GFP constructs showed that both MoBar-A and MoBar-B displayed punctate localization pattern at the inner periphery of the conidia cell and also formed an enclosure around certain internal organelles during vegetative and infectious development of the rice blast fungus (Fig. 2a). Furthermore, GPCR mediated assessment of the expression level of MoBAR-A and MoBAR-B at different stages of infection showed that MoBAR-A has a higher expression level at all stages of $M$. oryzae
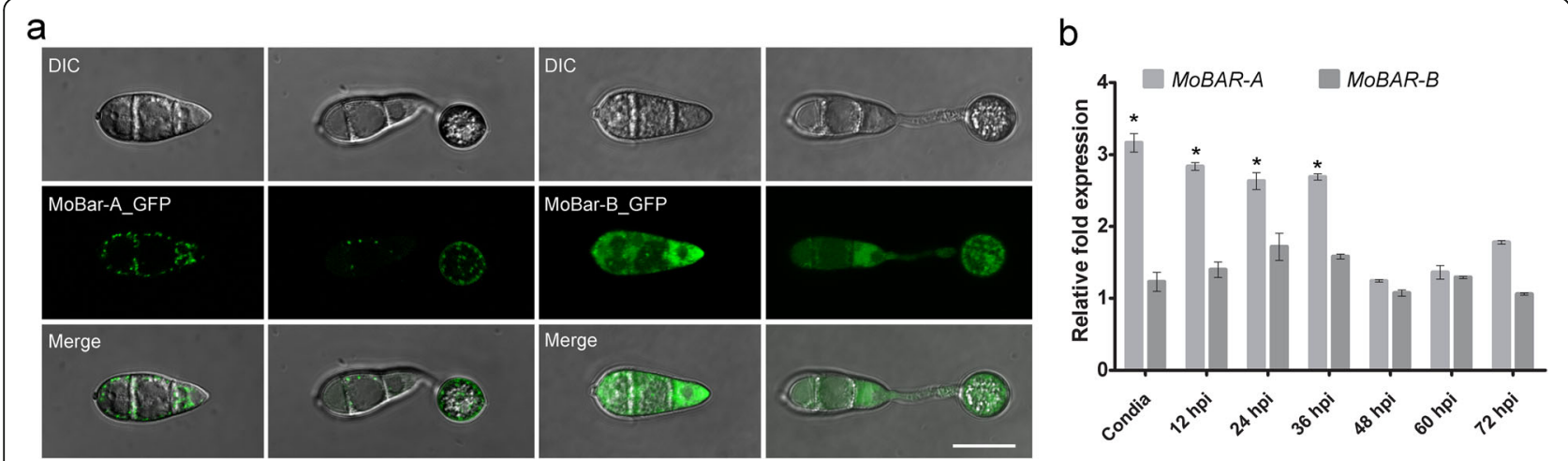

Fig. 2 Subcellular localization of MoBar-A and MoBar-B in Magnaporthe oryzae and the expression level of their respective genes during fungal infection. a The localization pattern of GFP/MoBar-A and MoBar-B/GFP in asexual spore and during spore germination and appressorium formation. Localization of GFP/MoBar-A and MoBar-B/GFP were visualized by Nikon laser confocal and laser excitation epifluorescence microscopy, the scale bar is $10 \mu \mathrm{m}$. $\mathbf{b}$ The relative expression level of MoBAR-A and MoBAR-B in the asexual spores and at different stages of infection in-planta by qPCR. The error bars represent standard errors from at least three independent replicates ( ${ }^{*}, P<0.05$ by t-test). The expression of $M$. oryzae actin gene in the mutants and the wild-type strain at each stage of infection was used as the internal control. The expression level of MOBAR-A and MOBAR-B during the development of vegetative hyphae was used as control stage and was assumed as unity (the expression level of MoBAR-A and MOBAR-B at hyphal stage $=1$ ) 
infection than MoBAR-B (Fig. 2b). These results indicated that although MoBar-A and MoBar-B displayed similar subcellular localization pattern, they likely exert differential influence on the infectious development of filamentous fungus.

\section{Generation of MoBAR-A and MoBAR-B deletion strains}

To ascertain the direct role of MoBar-A and MoBar-B in morphological and infectious development of the rice blast fungus, we used homologous recombination approach to generate targeted gene deletion mutants. Potential MoBAR-A and MoBAR-B deletion transformants were screened by PCR with gene-specific primer pairs (Additional file 1: Table S2). We proceeded further to confirm the successful deletion of MoBAR-A and $M o B A R-B$ with Southern-blotting assays (Fig. 3). Results obtained from these confirmation assays showed that the open reading frame (ORF) of both $M o B A R-A$ and $M o B A R-B$ were successfully replaced through a single insertion of hygromycin phosphotransferase (hph) ORF to yield $\triangle$ Mobar- $A$ and $\triangle M o b a r-B$ strains without the lethal phenotype (Abdul et al. 2018).

\section{The influence of MoBAR-A and MoBAR-B deletion on the} vegetative growth and asexual development of $M$. oryzae To assess the contributions of MoBAR-A and MoBAR-B to vegetative growth as well as the general morphological development of $M$. oryzae, colony diameter and aerial hyphae characteristics of $\triangle$ Mobar-A, $\Delta$ Mobar-B mutant strains, their respective complemented strains ( $\triangle$ Mobar-A_Com. and $\triangle$ Mobar-B_Com.), the double gene deletion strain ( $\triangle$ Mobar-A/AMobar-B) along with the wild-type strain (Guy11) grown on nutrients sufficient media "complete media" $(\mathrm{CM})$ for 10 days were measured. We observed that the deletion of MoBAR-A triggered a significant reduction in colony diameter, whereas the deletion of $M o B A R-B$ has no adverse effect on the morphological development of $\triangle M o b a r-B$ strains. We also showed that $\triangle$ Mobar-A/ $\triangle$ Mobar-B, the double gene deletion mutant (deletion of $M o B A R-B$ on $\triangle M o$ bar- $A$ background), did not alter the growth defects a

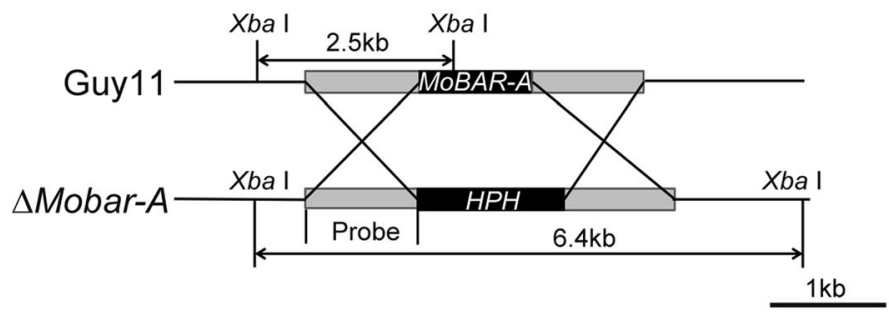

b

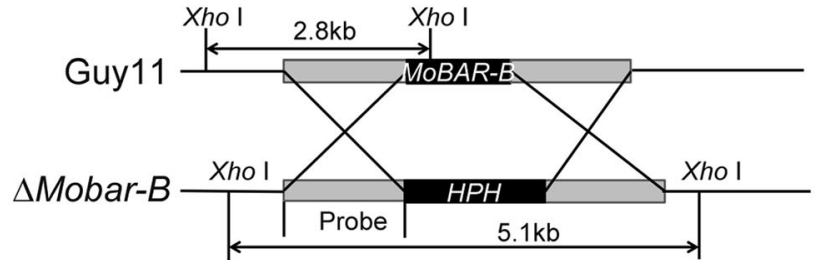

C

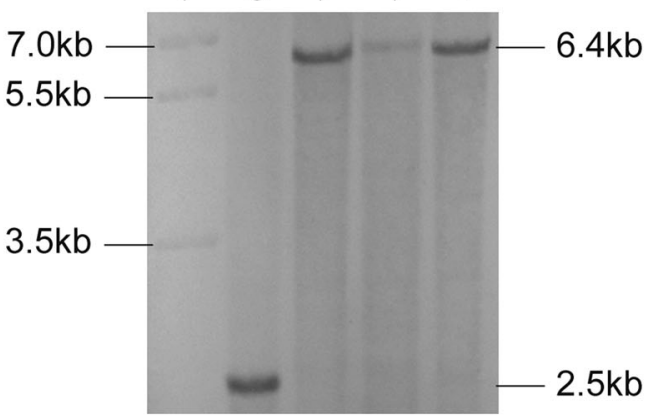

d

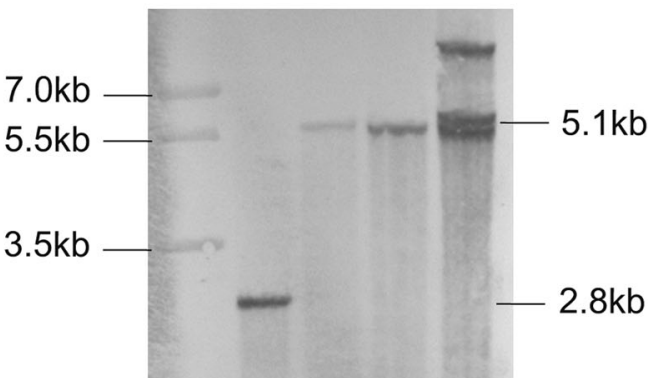

Fig. 3 Targeted deletion of MOBAR-A and MOBAR-B in Magnaporthe oryzae. a and $\mathbf{b}$ Schematic maps showing targeted disruption of MoBAR-A and MOBAR-B, respectively, with homologs recombination strategy. $\mathbf{c}$ and $\mathbf{d}$ Southern blot results showing successful replacement of MoBAR-A and MOBAR-B, respectively, by single insertion of hygromycin phosphotransferase (hph) ORF at MoBAR-A and MoBAR-B loci 
displayed by the $\triangle$ Mobar-A strain (Fig. 4a, b). From these observations, we inferred that $M o B A R-A$ and $M o B A R-B$ play a functionally unrelated role in the morphogenesis of the rice blast fungus.

Although it has been suggested that the I-BAR domain-containing protein Rvs167 in association with septin (MoSep3 and MoSep5) mediates appressorium formation and development in $M$. oryzae (Dagdas et al. 2012), there is no or limited amount records on the direct contribution of other BAR domain-containing proteins to the production of asexual spore and infectious development of the rice blast fungus. To gain insights into the influence of $M o B A R-A$ and $M o B A R-B$ on sporulation and infectious development of $M$. oryzae, we accordingly evaluated sporulation characteristics of the $\Delta$ Mobar-A, $\triangle$ Mobar-B, $\triangle$ Mobar-A/DMobar-B, $\Delta$ Mobar$A \_$Com. and $\triangle M o b a r-B \_C o m$. strains in comparison with the wild-type strain. It was showed that targeted disruption of $M o B A R-A$ caused a drastic reduction in the production of asexual spores, while the number of spores produced by the $\Delta$ Mobar-B strain was comparable to that produced by the wild-type strain. We also noticed that the sporulation characteristics of the $\Delta M o$ bar-A/ $\triangle$ Mobar- $B$ strain were consistently similar to those of the $\triangle$ Mobar- $A$ strain (Fig. 4c, d). Taken together, we inferred that $M o B A R-A$ plays an exclusive and crucial role in the conidiogenesis of $M$. oryzae.

\section{Influence of MoBAR-A and MoBAR-B deletion on the pathogenesis of $M$. oryzae}

In an attempt to unravel the impact of $M o B A R-A$ and $M o B A R-B$ deletion on the pathogenesis of the rice blast fungus, hyphae of the respective mutant, complemented, and the wild-type strains cultured in liquid CM were deployed as inoculum to inoculate intact and injured barley leaves. Findings from these bio-assays revealed

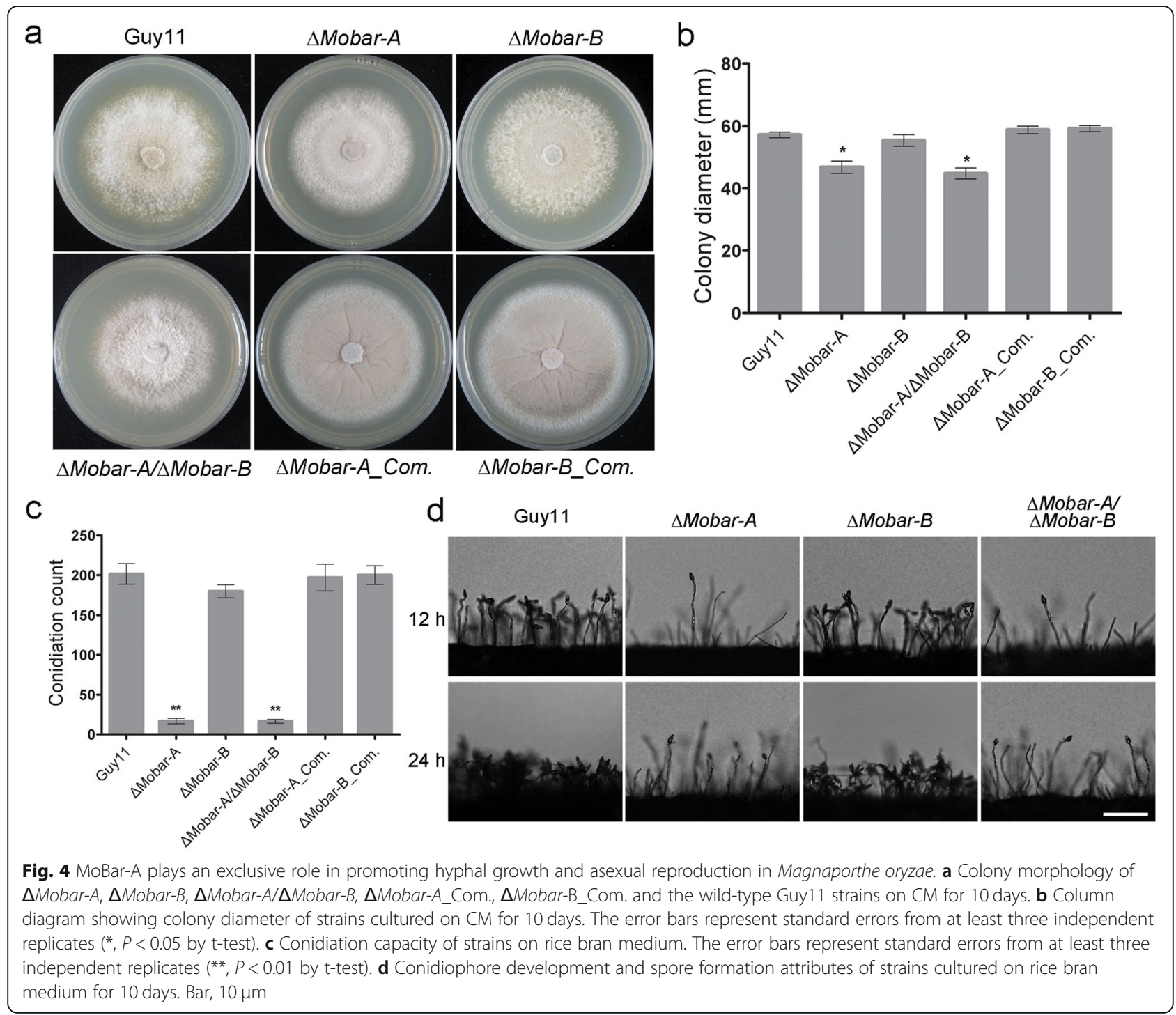


that while the $\Delta$ Mobar- $A$ and $\Delta$ Mobar-A/ $\Delta$ Mobar-B strains lost the ability to penetrate intact barley leaves and initiate hyphae-mediated infection, the $\Delta$ Mobar- $B$ strains, on the other hand, caused typical blast lesions on both intact and injured barley leaves (Fig. 5a). Although $\Delta$ Mobar- $A$ and $\Delta$ Mobar-A/DMobar-B strains were capable of inflicting hyphae-mediated blast lesions on injured barley leaves, the virulence level of these two strains reduced drastically compared to that of the $\Delta M O$ bar- $B$, complemented and the wild-type strains (Fig. $5 \mathrm{a}$ ). Because the $\Delta$ Mobar- $A$ and $\Delta$ Mobar-A/ $\Delta$ Mobar- $B$ strains do not produce enough spores for spray inoculation, we accordingly initiated spore-mediated infection assays by placing drops of spore suspensions of the respective strains on intact and injured barley leaves.

Additionally, spore suspensions prepared with spores from $\Delta$ Mobar-B, $\triangle$ Mobar-A_Com. and $\Delta$ Mobar-B_Com. strains were used to inoculate seedlings of susceptible rice cultivar 'CO39' independently. We also showed that double disruption of MoBAR-A and MoBAR-B did not alter both the penetration abilities and virulence characteristics of $\triangle$ Mobar- $A$ and $\triangle$ Mobar- $B$ during spore- mediated infection (Fig. 5b, c). However, the few appressorium-like structures produced by the $\Delta$ Mobar$A$, and $\Delta$ Mobar-A/DMobar-B strains during hyphaemediated infection failed to penetrate and colonize host tissues (Fig. 5d). These results suggest MoBAR-A likely plays an indispensable role in promoting hyphaemediated penetration of host tissues for successful development of rice blast disease.

\section{MoBAR-A but not MoBAR-B is essentially required for the formation of hypha-tip appressorium-like structure in $M$. oryzae}

In addition to asexual spores, $M$. oryzae is also capable of initiating blast infection with the use of hyphae (Kong et al. 2013). During the initiation of hyphae-mediated invasion, the rice blast fungus develops melanized and dome-shaped appressorium-like structures at the hyphal tip. These appressorium-like structures later differentiate into rigid structures known as penetration-pegs that allow the blast fungus to rapture the leaf cuticles physically and successfully invade the host cells (Kong et al. 2013; Ryder and Talbot 2015). To unravel factors a

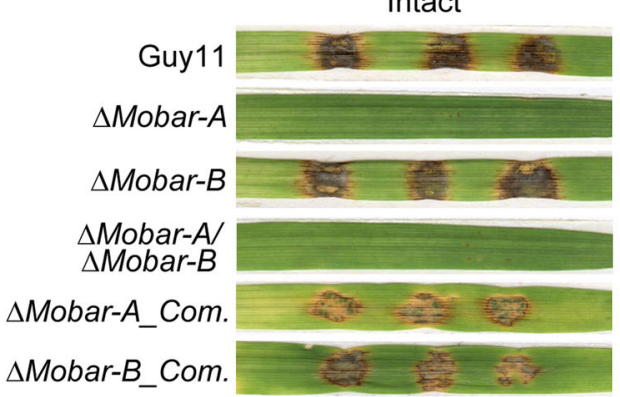

b

Intact

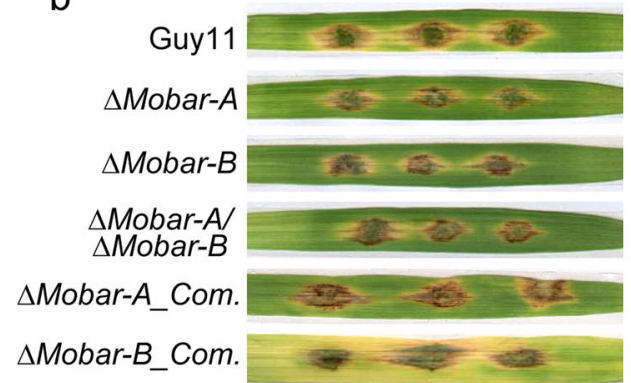

Injured

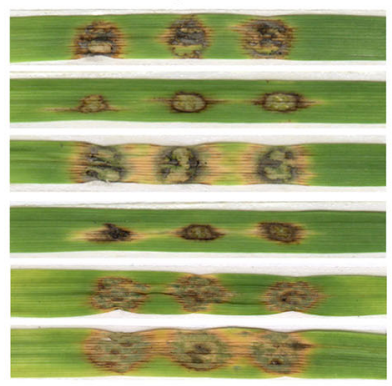

Injured

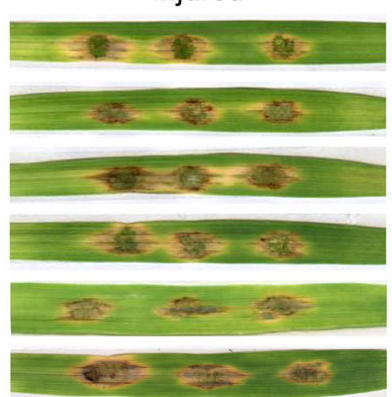

C

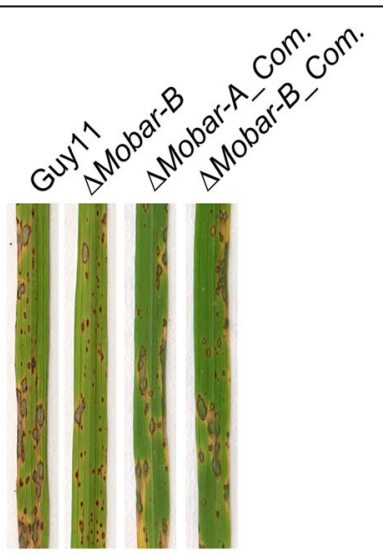

d

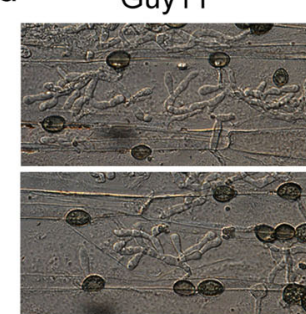

$\Delta$ Mobar-B

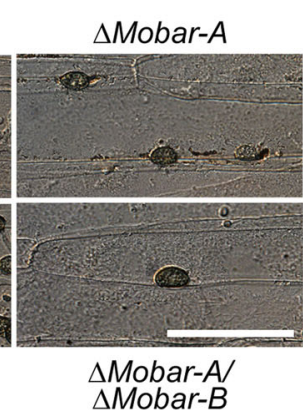

Fig. 5 MoBar-A contributes exclusively to hyphae-mediated initiation of blast infection on intact host tissues. a Development of blast infection on intact and injured barley leaves inoculated independently with hyphae harvested from the wild-type, $\Delta$ Mobar-A, $\Delta$ Mobar-B, $\Delta$ Mobar-A/ $\Delta$ Mobar-B, $\Delta$ Mobar-A_Com. and $\Delta$ Mobar-B_Com. strains. b Development of blast infections on intact and injured barley leaves inoculated independently with drops of spore suspension (5-10 spores $/ 20 \mu \mathrm{L}$ containing $0.02 \% \mathrm{v} / \mathrm{V}$ Tween20) obtained from the wild-type, $\Delta$ Mobar-A, $\Delta$ Mobar-B, $\Delta$ Mobar-A/ $\triangle$ Mobar-B, $\triangle$ Mobar-A_Com. and $\triangle$ Mobar-B_Com. strains. c Disease lesions formed on susceptible rice cultivar 'CO39' after independent spray inoculation with spore suspension $\left(1 \times 10^{3} \mathrm{spores} / \mathrm{mL}\right.$ containing $0.02 \%$ Tween20) obtained from wild-type, $\Delta$ Mobar-B, $\Delta$ Mobar-A_Com. and $\Delta$ Mobar-B_Com. strains. d Penetration and colonization capabilities of the $\Delta$ Mobar-A, $\Delta$ Mobar-B, $\Delta$ Mobar-A/ $\Delta$ Mobar-B and the wild-type strains cultured on rice bran medium for 10 days. Bar, $10 \mu \mathrm{m}$ 
accounting for the failure of $\triangle$ Mobar-A and $\triangle$ Mobar-A/ $\triangle M o b a r-B$ strains to invade intact leaf tissues, we monitored the development of hyphae tip appressorium-like structures in the $\triangle$ Mobar-A, $\triangle$ Mobar-B, $\triangle$ Mobar-A/ $\triangle$ Mobar- $B$, and wild-type strains by inoculating the individual strains on barley leaves and appressorium inducing hydrophobic slide covers. From these investigations, we observed that single deletion of MoBAR-A, and the combined deletion of MoBAR-A and MoBAR-B significantly compromised ( $99 \%$ reduction) the formation of appressorium-like structures (Fig. 6a, b). These results demonstrated that $M o B A R-A$ plays an essential role in the development of appressorium-like structures in M. oryzae.
Furthermore, to ascertain the impact of $M o B A R-A$ and $M o B A R-B$ disruption on the expression of appressorium and appressorium-like structure associated genes, including MoCHS7, MoCON7, MoCPKA, MoMAC1, MoMSB2, MoMST12 MoPMK1, MoSFL1 and MoSHO1. We performed qPCR assays to evaluate the relative expression level of each of these genes in the $\triangle$ Mobar- $A$, $\Delta$ Mobar-B, and $\Delta$ Mobar-A/ $\Delta$ Mobar- $B$ compared with that in the wild-type strain during appressorium-like structure formation stage using primers specific to each target gene. It was showed that the deletion of MoBAR$A$ and $M o B A R-B$ triggered down-regulation of all the above appressorium-like structure associated genes in the exception of MoPMK1. We also noticed that single,

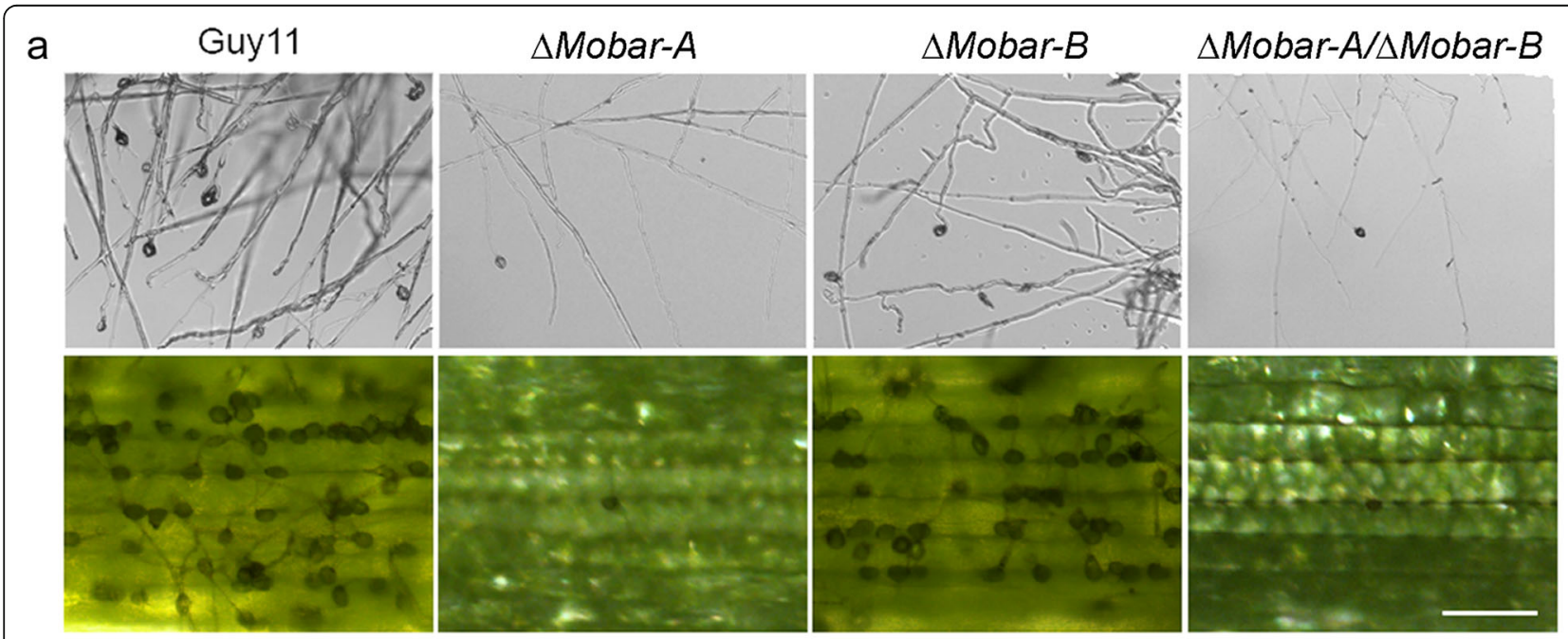

b

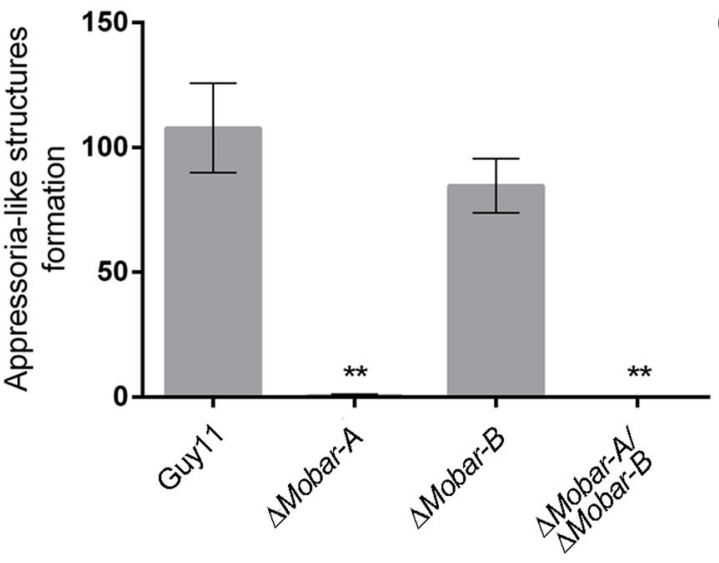

C

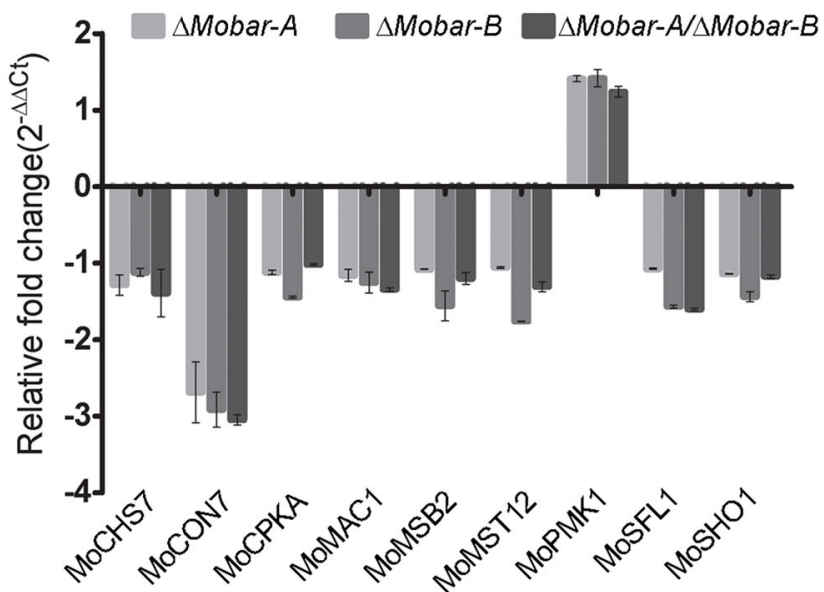

Fig. 6 MoBar-A essentially promotes the formation of appressorium-like structures in Magnaporthe oryzae. a Development of appressorium-like structures by the $\Delta$ Mobar-A, $\Delta$ Mobar-B, $\Delta$ Mobar-A/ $\Delta$ Mobar-B, and the wild-type strains inoculated on artificial appressorium-inducing hydrophobic cover-slides and barley leaves. scale bar, $10 \mu \mathrm{m}$. $\mathbf{b}$ Column digram showing the number of appressorium-like structures produced by the individual strains inoculated on barley leaves. The error bars represent standard errors from at least three independent replicates $\left(^{* *}, P<0.01\right.$ by ttest). $\mathbf{c}$ The expression level of genes associated with the formation of appressorium-like structures in the $\Delta$ Mobar- $A, \Delta$ Mobar-B and $\Delta$ Mobar- $A$ / $\triangle$ Mobar-B strains compared with that in the wild-type strain. The GPCR results were generated from three independent biological replications with three technical replicates. The error bars represent mean \pm SD 
as well as combined deletion of MoBAR-A and MoBAR$B$ exerted the most significant suppressive effects on the expression of MoCON7 (Fig. 6c). These results indicated that both MoBAR-A and MoBAR-B influence the expression of appressorium-like structure related genes in a different magnitude, but whether the two BAR domaincontaining proteins characterized in this study directly interacts with these appressorium-like structure associated genes in M. oryzae is not yet known.

\section{Influence of MoBAR-A and MoBAR-B deletion on the expression of membrane-associated tubulation sculpturing genes}

To gain insights into the direct or indirect contributions of MoBAR-A and MoBAR-B to cell membrane and cell wall stress tolerance of $M$. oryzae, we assayed the growth of $\Delta$ Mobar-A, $\Delta$ Mobar-B, $\Delta$ Mobar-A/DMobar-B, and the wild-type strains on $C M$ supplemented with cell membrane and cell wall stress-inducing osmolytes including DTT, $\mathrm{NaCl}$, Calcofluor White (CFW) and Conge Red (CR). Growth records obtained from these assays showed that the deletion of MoBAR-A and the double deletion of MoBAR-A and MoBAR-B partly compromised cell membrane and cell wall integrity and hence, rendered the $\Delta$ Mobar- $A, \Delta$ Mobar-A/ $\Delta$ Mobar- $B$ selectively sensitive to DTT, SDS and CFW administered as membrane and cell wall stress-inducing osmolytes. However, the targeted replacement of $M o B A R-B$ has no adverse effects on both membrane and cell wall stress tolerance (Fig. 7a, b). These results indicated that $M o B a r-A$ directly or indirectly enforces stress tolerance of $M$. oryzae while $M o B a r-B$, on the other hand, plays an insignificant or redundant role in the stress tolerance of the rice blast fungus.

Furthermore, we instituted qPCR assay to assess the impact of MoBAR-A, MoBAR-B, and MoBAR-A/MoBAR$B$ deletion on the expression of 13 genes associated with membrane tubulation and vesicle transport during the vegetative growth phase of respective mutant strains. Results obtained from these analyses showed that although targeted and the combined deletion of MoBAR-A and $M o B A R-B$ resulted in the down-regulation of 13 membrane tubulation related genes, the deletion of MoBAR$A$ exerted the highest suppression effect on the expression of oxysterol binding protein-1 gene (MoOSBP-1) and vesicle transport V-SNARE protein gene (MoVTI1) in the $\triangle$ Mobar- $A$ strains. We also observed targeted deletion of MoBAR-B had a more significant suppression effect on the expression of oxysterol binding protein-2 gene $(M o O S B P-2)$, integral membrane protein sed5 gene (MoSED5), and hypothetical protein gene (MGG_12614) while the expression of combined deletion of MoBAR-A and $M o B A R-B$ exacerbated the down-regulation of
$M o O S B P-1$ and MoVTI1 in addition to oxysterol binding protein-4 gene (MoOSBP-4) (Fig. 7c).

In response to the observation that the disruption of $M o B A R-A$ and MoBAR-B resulted in a general downregulation of genes related to membrane tubulation in the rice blast fungus, we subsequently deployed yeast two-hybrid assay to ascertain whether MoBar-A or MoBar-B physically (directly) interacts with the corresponding proteins. The results obtained from proteinprotein interaction assays showed that both MoBar-A and MoBar-B do not directly interact with those membrane tabulation related proteins (Fig. 7d). From these observations, we speculated that the down-regulation pattern exhibited by the 13 membrane tabulation associated protein genes following targeted disruption of $M o B A R-A$ and MoBAR-B is likely due to perturbation in membrane integrity in response to membrane imbalance caused by dysfunction of MoBar-A and MoBar-B.

\section{Discussion}

Membrane remodeling plays essential roles in facilitating the progression of numerous membrane-mediated cellular trafficking processes, including endocytosis and reorganization of actins (Anggono and Robinson 2009; Pollard et al. 2016). BAR domain proteins have been identified as one of the crucial membrane-associated proteins that promote membrane curvature, and the vesiculation of target proteins to curved membranes (Mim and Unger 2012; Franquelim et al. 2018). More than 200 BAR domain-containing proteins have been identified mostly in eukaryotes. According to structure conformation and phylogenetic properties, BAR domaincontaining proteins are classified as F-BAR, N-terminal amphipathic helix BAR (N-BAR), inverse (I-BAR), Golgi vesicle protein of $36 \mathrm{kDa}$ (Gvp36), arfaptin, nadrin, and GRAF1 (Peter et al. 2004; Stanishneva-Konovalova et al. 2016). These crescent-shaped BAR domains bind to membranes and alter the matrix dynamic of membranes inducing either convex or concave curvatures. In addition to the BAR domain, most of the wellcharacterized BAR domain proteins contain at least one additional functional domains such as SH3-domain and PX domain (Peter et al. 2004; Vergés 2016). Proteins containing only F-BAR domain have been implicated in membrane trafficking, cell morphology, cell motility, and cell division (Liu et al. 2015). Besides the F-BAR domain, the independent function of other BAR domains such as arfaptin, N-terminal amphipathic helix BAR (N-BAR), inverse (I-BAR), Golgi vesicle protein of $36 \mathrm{kDa}$ (Gvp36) (Inadome et al. 2005) during both physiological and pathological development of phytopathogenic fungi is not well understood.

Results obtained from phylogenetic analysis of two uncharacterized proteins containing a N-terminal amphipathic helix 


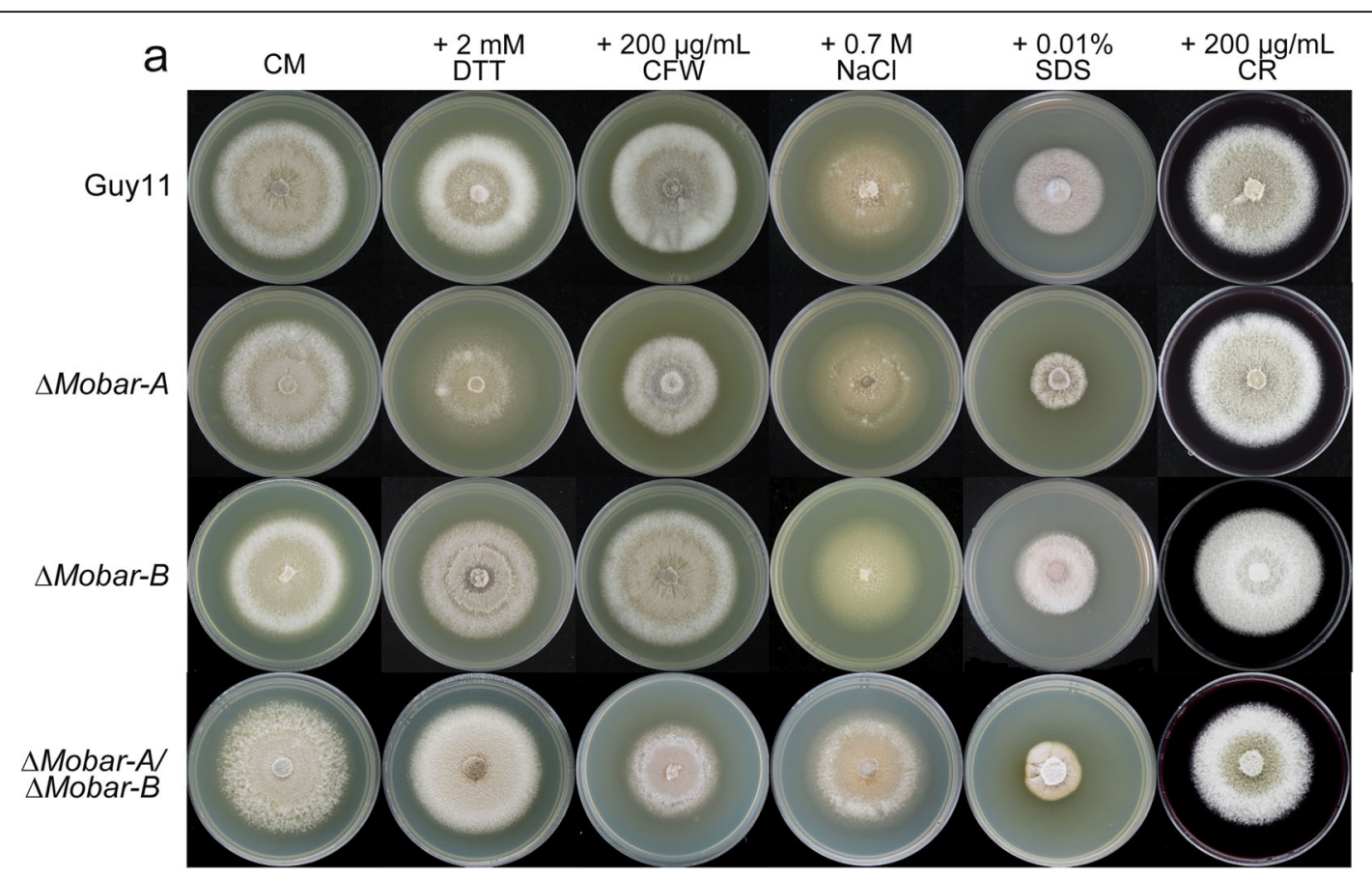

b

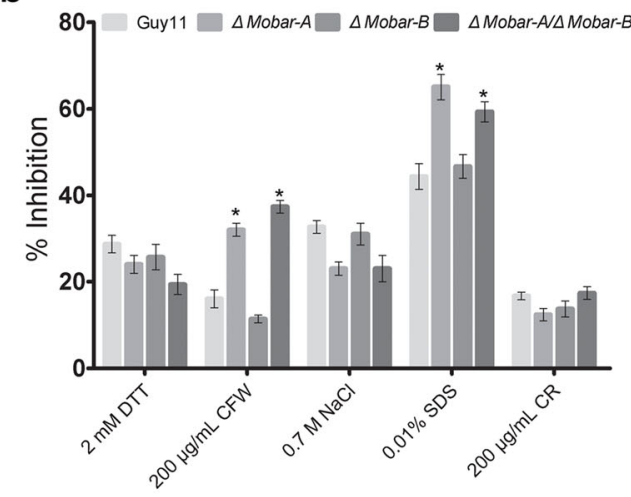

d

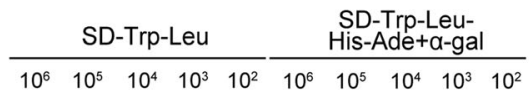

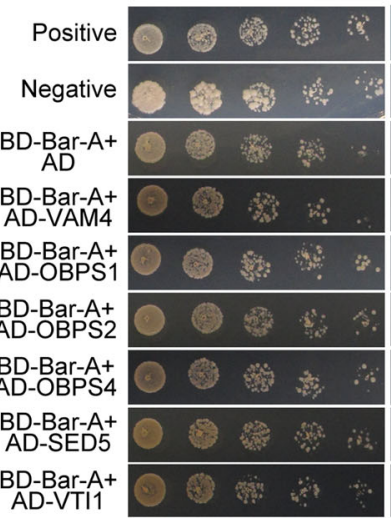

BD-Bar-A-
C

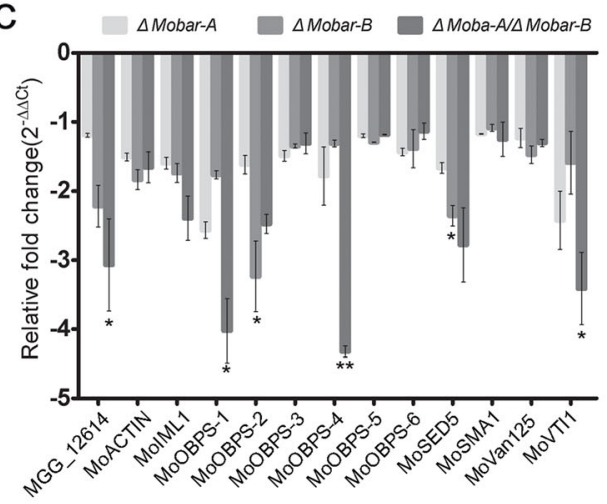

e

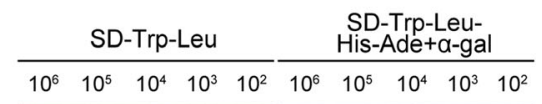

$\mathrm{BD}-\mathrm{Bar}-\mathrm{B}+$
$\mathrm{AD}$

BD-Bar-B+
AD-VAM4

AD-VAMt

BD-Bar-A+
AD-OBPS1

BD-Bar-B+
AD-OBPS2

BD-Bar-B+

BD-Bar-B+

AD-SED5

BD-Bar-B+
AD-VT11

$\mathrm{BD}-\mathrm{Bar}-\mathrm{A}+$

AD-Bar-B
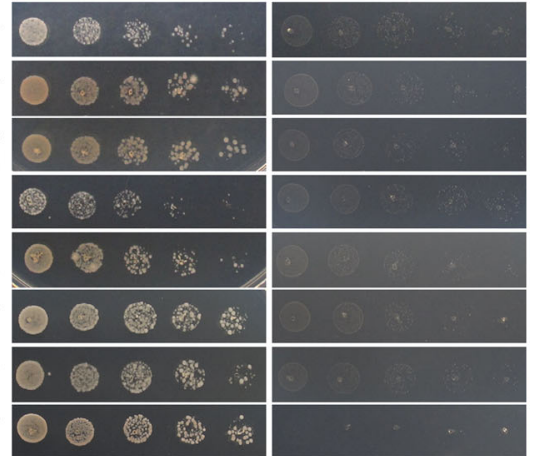

Fig. 7 (See legend on next page.) 


\section{(See figure on previous page.)}

Fig. 7 BAR domain-containing proteins regulate the expression of membrane tubulation related genes. a The inhibitory effects of cell oxidative and reductive stress-inducing osmolytes on the vegetative growth of the $\Delta$ Mobar $-A, \Delta$ Mobar-B, $\Delta$ Mobar-A/ $\Delta$ Mobar-B, and the wild-type strains cultured on CM media supplemented independently with $2 \mathrm{mM}$ DTT, $0.7 \mathrm{M} \mathrm{NaCl}, 200 \mu \mathrm{g} / \mathrm{mL}$ Calcofluor White (CFW), $0.01 \% \mathrm{SDS}$ and $200 \mu \mathrm{g} / \mathrm{mL}$ Conge Red (CR) for 10 days. $\mathbf{b}$ Growth responses of $\Delta$ Mobar-A, $\Delta$ Mobar-B, $\Delta$ Mobar-A/AMobar-B, and the wild-type strains to the different oxidative and reductive stress-inducing osmolytes. Error bars represent standard errors from three independent replicates (*, $P<0.05$ by t-test). $\mathbf{c}$ The expression levels of putative membrane and membrane-associated genes in the $\Delta$ Mobar-A, $\Delta$ Mobar-B, and $\Delta$ Mobar-A/ $\Delta$ Mobar-B strains during vegetative growth. The qPCR results were obtained from three independent biological replications with three technical replicates. Error bars represent standard errors (*, $P<0.05 ;{ }^{* *}, P<0.01$ by t-test). $\mathbf{d}$ Yeast-two-hybrid assay represent protein-protein level interaction between MoBar-A and putative membrane associated proteins in M. oryzae. e The interaction pattern of MoBar-B with putative membrane associated proteins in M. oryzae

BAR or BAR_2 domain indicated that they are phylogenetically unrelated $(<17 \%$ similarity). Further alignment conducted with domain motif sequence showed that one protein denoted as MoBar-A contains endophilin-A (EndoA) NBAR domain and shared a high domain motif sequence similarity (> 70\%) with BAR-domain containing proteins from $S$. brasiliensis and $N$. crassa while the other protein, MoBar-B, shared high $(>80 \%)$ motif sequence similarity with BAR_2 domain proteins in S. schenckii and Sc. sclerotiorum. The phylogenetic and domain motif differences exhibited by MoBar-A and MoBar-B and coupled with the knowledge that the classification of BAR domains reflect their structure and functional differences (Kessels and Qualmann 2015), subsequently informed our conclusion that MoBar-A and MoBar-B likely play distinct roles in the physiological and infectious development of $M$. oryzae.

BAR domain-containing proteins are membraneassociated proteins (Olivera-Couto et al. 2011). The crescent positively charged BAR domain found in these proteins foster their binding to cell membranes (Peter et al. 2004). The association of BAR domain-containing proteins with the cell membrane induces membrane curvature, stabilizes curvature triggered by recruitment cytoplasmic proteins of varying sizes to membranes and substantially modulates membrane trafficking processes (Pollard et al. 2016). MoBar-A and MoBar-B displayed punctate localization pattern at the inner periphery and around organelles with varying sizes in a manner reminiscence of "wrist beads." Since BAR domain proteins are membrane-associated proteins rather than membrane proteins, it is not surprising that the fusion of MoBar-A and MoBar-B with GFP reporter protein did not illuminate the entire cell membrane. We accordingly reasoned that the punctate fluorescence reflects lattices of the GFP-MoBar-A and MoBar-B-GFP on the membranes.

Membrane and vesicular trafficking processes such as endocytosis, vacuolar tethering and fusion, retrograde trafficking, and snaring, play crucial roles in morphological, reproductive and infectious development of the rice blast fungus (Zhang et al. 2017). The understanding that BAR domain proteins play an indispensable role in driving clathrin-mediated endocytosis and regulating the biogenesis of transport carriers and the reorganization of the actin cytoskeleton through the induction of membrane curvature underscores the relevance of BAR domain in promoting fungal pathogenesis (Douglas et al. 2009). We observed that the expression level of MoBAR$A$ remained relatively high as compared with that of $M o B A R-B$ during early and very late stages of infection. Additionally, results obtained from evaluating growth, sporulation, pathogenicity and virulence characteristics of $\triangle$ Mobar- $A, \Delta$ Mobar-B, and $\triangle$ Mobar $-A / \Delta$ Mobar $-B$ strains showed that while $M o B A R-B$ is dispensable of growth, sporulation, and pathogenesis of $M$. oryzae, targeted replacement of $M o B A R-A$ attenuated growth, sporulation and exclusively abolished hyphae-mediated blast infection. BAR domain-containing proteins (MoBar-A and MoBar-B) influence the physiological and pathological development of the rice blast fungus differently. Also, we showed that targeted gene disruption of $M o B A R-B$ from $\triangle M o b a r-A$ mutant ( $\triangle$ Mobar- $A$ ) $\triangle M o b a r-B)$ did not alter growth, sporulation, as well as hyphae-mediated pathogenicity defects displayed by the $M o B A R-A$ single gene deletion strain, suggesting that MoBar-A and MoBar-B do not play overlapping roles and also could not functionally complement each other. We further speculated that MoBar-B is likely a functionally redundant BAR domain-containing protein in M. oryzae.

The rice blast fungus deploys asexual spores and hyphae as propagules for initiating blast infection on tissues of susceptible host plants (Giovannetti et al. 1993; Kong et al. 2013; Zhang et al. 2017). Initiation and the subsequent development of asexual spore- and hyphaemediated blast infection involve the formation of a dome-shaped infectious structure called appressorium and appressorium-like structure in the germinating spore and hypha, respectively (Kong et al. 2013). Functional appressorium later differentiates into a rigid penetration-peg that facilitates the physical penetration of host cells by the invading blast pathogen (Meng et al. 2009; Samalova et al. 2017). Previous research showed that different molecular mechanisms regulate the formation and development of appressoria (spore appressoria) and appressorium-like structures in $M$. oryzae (Zhang et al. 2017). MoBAR-A deletion attenuates the formation 
of appressorium-like structures in the $\triangle M$ Mobar- $A$ and $\triangle$ Mobar-A/AMobar-B strains. The $\triangle$ Mobar- $A$ and $\triangle M o b a r-A / \Delta M o b a r-B$ strains also loss the ability to induce hyphae-mediated blast infection.

Conversely, the spore-mediated infection characteristics including conidia germination, appressorium formation and subsequent infection exhibited by the MoBAR$A$, and MoBAR-A/MoBAR- $B$ defective strains were comparable to the wild-type strain. Also, the disruption of $M o B A R-A$ selectively down-regulated of genes associated with pathways that are involved in the regulation of appressorium-like structures in filamentous fungi. From these observations, we posited that different membranes dynamics control trafficking, vesiculation, and cellular transport processes that directly or indirectly regulate the development of appressoria and appressorium-like structures in filamentous phytopathogenic fungi.

Additionally, we showed that targeted gene disruption of both MoBAR-A and MoBAR-B significantly and differentially influence the expression pattern of appressorium- and appressorium-like structure-related genes during infectious development of $M$. oryzae. The selective influence exerted by deletion of MoBAR-A and MoBAR-B on the expression of these genes aligned to different cellular pathways further confirmed previous findings that different cellular and developmental pathways regulate the formation of different types of infectious structures in the rice blast fungus $(\mathrm{Xu}$ and Hamer 1996; Liu et al. 2011). From these results, we speculated that different BAR domains likely induce differential conformational changes in membranes to trigger the differential activation of the relevant pathway required for the development of specific infectious structures in M. oryzae under some sets of hosts or environmental conditions.

Kinases are a group of enzymes that add phosphates to serine, threonine, and tyrosine residues of proteins to trigger a post-translational modification. These phosphorylated proteins participate in cell cycle and diverse signal transduction processes (Hanks and Hunter 1995; Garcia-Garcia et al. 2016). Previous reports showed that unlike other kinases identified in the rice blast fungus genome, MoPmk1 exclusively regulates appressorium formation and the development of appressorium-like structures in $M$. oryzae. Although our results also demonstrated that the deletion of MoBAR-A compromised the development of appressorium-like structures in the $\triangle M o b a r-A$ strains, the expression of MoPmk1 was higher in the $\triangle$ Mobar-A strain. We speculated that MoPmk1 and MoBar-A likely regulate the development of appressorium-like structures in $M$. oryzae independently through the modulation of different proteins that are exclusively associated with the development of appressorium-like structures.

Cell membranes help in providing defining shapes for cell and organelles and as well functions as a biological barrier that limits the influx and efflux of diverse materials in and out of the cell (Lodish et al. 2008). Besides these fundamental roles, cell membrane also provides an anchorage for numerous transitory or membrane-bound proteins and bio-molecules and facilitates the intercellular and extra-cellular trafficking of vesicles, organelles, proteins, and cargoes. The Cell membrane also undergoes structural and conformational changes in response to environmental stimuli (Lodish et al. 2008). The recruitment of proteins to the membrane and the prevailing interaction between membrane proteins and membrane-associated proteins exert a profound influence on membrane topology, conductivity, and membrane-associated trafficking processes. Here, we observed that the $\Delta$ Mobar-A and $\Delta$ Mobar-A/DMobar-B strains generated in this study displayed selective sensitivity towards reductive and oxidative stress, while $\Delta$ Mobar- $B$ strains were immune to the membrane and cell wall-associated reductive and oxidative stressinducing osmolytes (Aliyu et al. 2019). We further demonstrated that the deletion of both MoBAR-A and $M o B A R-B$ resulted in differential but general downregulation of membrane-associated genes.

On the Contrary, no physical interactions were recorded between MoBar-A, or MoBar-B and the putative membrane proteins examined in this study. Proteins containing the positively charged BAR domains bind to cell membranes (negatively charged) (Stanishneva-Konovalova et al. 2016). We asserted the binding of BAR domain proteins to membranes produces counter effects that promote membrane stability and drive membraneassociated biological processes, including the expression of membrane-associated proteins. Furthermore, we deduced that the deletion of MoBAR-A and MoBAR-B likely upset membrane stability and indirectly triggered the suppression of membrane proteins.

\section{Conclusions}

The observation that two putative BAR domaincontaining proteins exerted distinct influence on both physiological and infectious development of the rice blast fungus, adequately underscored the need for extensive characterization of the numerous BAR domaincontaining proteins identified in the globally destructive fungus. Unraveling the influence of BAR domainmediated membrane dynamics on the pathogenesis of $M$. oryzae will further enhance efforts aimed at developing sustainable blast control strategies.

\section{Methods}

Fungal strains and culture conditions

Magnaporthe oryzae strain (Guy11) gifted by Dr. Didier Tharreau (CIRAD, Montpellier, France) was used as the parental background for generating $M o B A R-A$ and 
MoBAR-B deletion mutant strains. Guy11 and its derivative mutant strains, along with their respective complementation strains were cultured on complete growth medium (CM: $0.6 \%$ yeast extract, $0.6 \%$ casamino acid, $1 \%$ sucrose, $1.5 \%$ agar) at $25^{\circ} \mathrm{C}$ following Chen et al. (2008). Sporulation was assayed after culturing mutant and the wild-type strains on rice bran medium (2\% rice bran, $1.5 \%$ agar, $\mathrm{pH} 6.0$ ) with a photoperiod of $12 \mathrm{~h}$ light/ $12 \mathrm{~h}$ dark for 10 days before scratching-off the vegetative hyphae and further incubating it under light for another 3 days. Samples for DNA extraction and protoplast generation were prepared by culturing the strains in liquid $\mathrm{CM}$ at $150 \mathrm{rpm}, 25^{\circ} \mathrm{C}$ for $2-3$ days. Sensitivity assays were conducted by culturing the respective strains on $\mathrm{CM}$ plates fortified with different stress-inducing osmolytes $(0.7 \mathrm{M}$ $\mathrm{NaCl}, 0.01 \%$ SDS, $200 \mu \mathrm{g} / \mathrm{mL}$ Congo red and $200 \mu \mathrm{g} / \mathrm{mL}$ Calcofluor white) (Aliyu et al. 2019).

\section{Construction of MoBAR-A and MoBAR-B single and double mutants and complementation}

Split-marker knockout vectors were constructed and used for targeted replacement of $M o B A R-A$ and $M o B A R-B$ in $M$. oryzae. To construct split-markers for MoBAR-A, $1.1 \mathrm{~kb}$ upstream and $1.2 \mathrm{~kb}$ downstream flanking fragments of $M o B A R-A$ were amplified with the primer pairs MoBAR1-AF/AR and MoBAR1-BF/BR, respectively. For $M o B A R-B$ split-markers, $1.1 \mathrm{~kb}$ upstream and $1.2 \mathrm{~kb}$ downstream flanking fragments of MoBAR-B were amplified with the primer pairs MoBAR2-AF/AR and MoBAR2-BF/BR, respectively (Additional file 1: Table S2). The resulting PCR products were ligated with hph cassette fragment amplified with primers HYG/F + HY/R and YG/R + HYG/R (Additional file 1: Table S2) by overlapping PCR. For the fungal transformation, protoplast preparation and transformation of $M$. oryzae were performed as described (Goswami 2012; Norvienyeku et al. 2017). The transformants were screened with PCR using ORF and UAH primer pairs for individual genes as listed in Additional file 1: Table S2. Potential MoBAR-A and MoBAR-B gene deletion mutants were further confirmed by Southern blotting. $\triangle$ Mobar- $A$ and $\triangle$ Mobar- $B$ strains were complemented following Norvienyeku et al. (2017).

\section{Genomic DNA isolation}

Total genomic DNA was extracted from $\triangle$ Mobar-A, $\Delta$ Mobar-B, $\Delta$ Mobar-A/AMobar-B, complementation, and wild-type Guy11 strains using the CTAB method (Aliyu et al. 2019). Briefly, the fungal strains were separately cultured in liquid media for 3 days at $28^{\circ} \mathrm{C}, 120$ rpm. Mycelia were harvested by filtration, and blotted dry with absorbent paper, frozen in liquid nitrogen then ground into a fine powder with a mortar and pestle in liquid nitrogen. The grounded mycelia were re-suspended in $1 \mathrm{~mL}$ of ice-cold lysis buffer $(150 \mathrm{mM} \mathrm{NaCl}, 50 \mathrm{mM}$ EDTA, $10 \mathrm{mM}$ Tris- $\mathrm{HCl}, \mathrm{pH} 7.4,30 \mu \mathrm{g} / \mathrm{mL}$ proteinase $\mathrm{K})$, transferred into $1.5 \mathrm{~mL}$ Eppendorf tube and stored at $4{ }^{\circ} \mathrm{C}$ to limit endonuclease activity during rehydration of the sample. SDS was added to a final concentration of $2.0 \%$, vortex-mixed and incubated at $65^{\circ} \mathrm{C}$ for $30 \mathrm{~min}$. After centrifugation at $16000 \times \mathrm{g}$ for $15 \mathrm{~min}$, the supernatant was transferred to a new sterile Eppendorf tube. The volume of supernatant was measured, and the $\mathrm{NaCl}$ with a concentration of $1.4 \mathrm{M}$ and one-tenth volume of $10 \%$ CTAB buffer (10\% CTAB, $500 \mathrm{mM}$ Tris- $\mathrm{HCl}, 100$ mM EDTA, pH 8.0) was then added. The solution was thoroughly mixed and incubated at $65^{\circ} \mathrm{C}$ for $10 \mathrm{~min}$. After cooling at $15^{\circ} \mathrm{C}$ for $2 \mathrm{~min}$, an equal volume of chloroform-isoamyl alcohol $(24: 1 \mathrm{v} / \mathrm{v})$ was added, thoroughly mixed and the tube was centrifuged at $16000 \times \mathrm{g}$ for $15 \mathrm{~min}$. The extraction process was repeated until the interface was clear. The supernatant was then pipetted into a new Eppendorf tube, containing 2 volumes of cold $100 \%$ ethanol. After DNA precipitation, the pellet was centrifuged at $16000 \times \mathrm{g}$ for $15 \mathrm{~min}$. Pellets obtained after centrifugation was washed with $70 \%$ ethanol and dried at room temperature. The resultant product was re-suspended in $100 \mu \mathrm{L}$ TE buffer with $0.002 \%$ RNase $(5 \mu \mathrm{g} / \mathrm{mL})$ and incubated at $37^{\circ} \mathrm{C}$ for $1 \mathrm{~h}$. The suspension was used as a template for amplifying upstream and downstream fragments of MoBAR-A, and MoBAR-B.

\section{Total RNA extraction}

The $\Delta$ Mobar-A, $\triangle$ Mobar- $B, \Delta$ Mobar-A/DMobar-B, complementation, and wild-type strains were cultured in liquid $\mathrm{CM}$ at $28^{\circ} \mathrm{C}, 120 \mathrm{rpm}$ for 3 days. Mycelia were harvested as described above and ground to homogeneity in liquid nitrogen. An equal weight of each sample was placed into a $1.5 \mathrm{~mL}$ sterilized Eppendorf tubes, suspended with $1 \mathrm{~mL}$ RNAiso, vortex-mixed vigorously, and then incubated at $25^{\circ} \mathrm{C}$ for $5 \mathrm{~min}$. Two hundred microliters of chloroform was added to the mix and vortexmixed for $15 \mathrm{~s}$ to get rid of proteins. The mixture was allowed to settle down at $25^{\circ} \mathrm{C}$ for $3 \mathrm{~min}$, and subsequently centrifuged at $16000 \times \mathrm{g}, 4^{\circ} \mathrm{C}$ for $15 \mathrm{~min}$. The resulting supernatant was pipetted into a new Eppendorf tube, $400 \mu \mathrm{L}$ of isopropanol was added, gently mixed and allowed to settle-down at $25^{\circ} \mathrm{C}$ for $10 \mathrm{~min}$. The suspension was centrifuged at $12000 \times \mathrm{g}, 4^{\circ} \mathrm{C}$ for $10 \mathrm{~min}$, then the supernatant was discarded, and $1 \mathrm{~mL}$ of $75 \%$ alcohol was added and centrifuged at $12000 \times \mathrm{g}, 4{ }^{\circ} \mathrm{C}$ for $5 \mathrm{~min}$. The supernatant was discarded, the precipitates were air-dried at $25^{\circ} \mathrm{C}$ for $5 \mathrm{~min}$ and diluted with RNAse free water, and $10 \times$ reaction buffer and DNase were added to prepare an initial solution of $200 \mu \mathrm{L}$ and incubated for $30 \mathrm{~min}$ at $37^{\circ} \mathrm{C}$, then heated at $65^{\circ} \mathrm{C}$ for $2 \mathrm{~min}$ in a water bath before adding more RNase free water to attain a final volume of $500 \mu \mathrm{L}$. An equal volume $(500 \mu \mathrm{L})$ 
of the mixture containing water-phenol, chloroform, and isopentanol in the ratio 25:24:1 was added to the RNA in suspensions, mixed gently and centrifuged at $16000 \times \mathrm{g}, 4{ }^{\circ} \mathrm{C}$ for $10 \mathrm{~min}$. About $200 \mu \mathrm{L}$ of supernatant was pipetted into a new Eppendorf tube before adding $500 \mu \mathrm{L}$ of absolute alcohol and stored at $-80^{\circ} \mathrm{C}$ for $2 \mathrm{~h}$. The solution was then centrifuged at $12000 \times \mathrm{g}, 4^{\circ} \mathrm{C}$ for $10 \mathrm{~min}$, the pelleted RNA was washed with $1 \mathrm{~mL}$ of $75 \%$ alcohol and centrifuged at $12000 \times \mathrm{g}, 4{ }^{\circ} \mathrm{C}$ for $5 \mathrm{~min}$, after which the supernatant was discarded and the precipitates were air-dried under room temperature for $5 \mathrm{~min}$. The precipitates were dissolved with DNA and RNA nucleotide-free water and store at $-80^{\circ} \mathrm{C}$ until use.

\section{Real-time RT-PCR assay}

To monitor the expression of MoBAR-A, and MoBAR-B in-planta and in the individual MoBAR-A, and MoBAR$B$ targeted gene deletion strains using real-time RT-PCR (RT-qPCR), total RNAs extracted from the $\triangle M o b a r-A$,

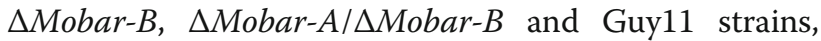
and plant tissues inoculated with the Guy11 strain were subjected to reverse transcription using $\mathrm{SYBR}^{\circ}$ Premix Ex. Taq ${ }^{\text {Tn }}$ (TliRNaseH Plus) purchase (Takara Biomedical Technology, Beijing Co. Ltd). A $25 \mu \mathrm{L}$ reaction mix was formulated as follows: $12.5 \mu \mathrm{L}$ Premix Ex-Taq, $1 \mu \mathrm{L}$ of each $10 \mu \mathrm{M}$ forward and reverse primers listed in Additional file 1: Table S2, and $1 \mu \mathrm{L}$ cDNA template. qRTPCR data was generated with Eppendorf Realplex2 mastercycler (Eppendorf AG 223341, Hamburg). Data analysis was conducted using delta delta-CT $(2-\Delta \Delta \mathrm{CT})$ method as described by (Livak and Schmittgen 2001; Aliyu et al. 2019). Actin was used as the internal control.

\section{Infection, penetration and appressorium-like structure assays}

$\Delta$ Mobar-A, $\triangle$ Mobar-B, $\Delta$ Mobar-A/ $\Delta$ Mobar-B, the complementation and the wild-type strains were cultured in liquid $\mathrm{CM}$ at $28^{\circ} \mathrm{C}, 120 \mathrm{rpm}$ for 3 days. The mycelia were washed with sterilized double-distilled water to remove remnants of culture medium and the excess water was drained off. The media-free mycelia were used to inoculate intact and injured barley leaves. The inoculated plants were kept in dark chamber ( $90 \%$ humidity) at $25^{\circ} \mathrm{C}$ for $24 \mathrm{~h}$, and later transferred into a growth chamber with a photoperiod of $12 \mathrm{~h}$ light/12 h dark. Disease development and lesion severity were assessed at 7 days post-inoculation (dpi) and used as a measure of pathogenicity and virulence characteristics of individual strains. Host penetration and colonization assays were performed by inoculating underside of barley leaves with media-free mycelia. Host invasion and colonization efficiencies of the respective strains were observed at 24 hours post-inoculation (hpi). For spore-mediated infection assays, $20 \mu \mathrm{L}$ of spore suspension (containing 5-10 spores) from wild type strain, mutants and the corresponding complemented strains was individually dropinoculated on intact and injured barley leaves, and the inoculated plants were kept under similar incubation conditions described for hyphae-mediated infection. To monitor the formation of appressorium-like structures. The fungal strains were cultured in liquid $\mathrm{CM}$ at $28^{\circ} \mathrm{C}$, $120 \mathrm{rpm}$ for 3 days. The mycelia were collected and then inoculated on both appressorium-inducing hydrophobic coverslips and barley leaves, and incubated under a humid condition at $26^{\circ} \mathrm{C}$ without light. The formation of appressorium-like structures was monitored and countered at 24 and 48 hpi under an optical microscope.

\section{Generation of MoBar-A and MoBar-B GFP fusion and complementation strains}

GFP-MoBar-A and MoBar-GFP fusion constructs were generated by amplifying $2.5 \mathrm{~kb}$ and $2.1 \mathrm{~kb}$ of the fulllength ORF including the respective promoters of $M o B A R-A$ and $M o B A R-B$ respectively using specific primer pairsBAR1-GF/BAR1-GR (MoBAR-A), and BAR2GF/BAR2-GR (MoBAR-B) (Additional file 1: Table S2) and inserted into the EcoRI/HindIII site of the pKNTG vector. The resulting fusion constructs GFP-MoBar-A and MoBar-B-GFP were transformed into protoplasts prepared from the $\triangle M o b a r-A$, and $\triangle M o b a r-B$ mutant strains. G418-resistant transformants were further screened by PCR with gene-specific pair of primers MoBAR1-ORF/MoBAR1-GFPR and MoBAR2-ORF/ MoBAR2-GFPR (Additional file 1: Table S2) and examined for GFP signals under a microscope.

\section{Microscopy assay}

Germinating conidia and appressorium were observed under the Nikon TiE system (Nikon, Japan).

\section{Supplementary information}

Supplementary information accompanies this paper at https://doi.org/10. 1186/s42483-019-0038-2.

Additional file 1: Figure S1. Phylogeny of $M$. oryzae Bar-A and Bar-B with fungi species across taxonomic groups. a Maximum likelihood phylogenetic relationship between $M$. oryzae Bar-A and Bar-A identified in fungal species from different taxon. $\mathbf{b}$ Maximum likelihood phylogenetic relationship between $M$. oryzae Bar-B and Bar-B identified in fungal species from different taxon. The Maximum likelihood phylogeny for BarA and Bar-B were tested with 1000 bootstrap replicates. Table S1. Full genus and species nomenclature of fungi groupings that were used in maximum likelihood neighbor joining tree for Bar-A and Bar-B. Table S2. Primers used in this study.

\section{Abbreviations}

ARP2/3: Actin-related proteins 2 and 3; BAR: Bin/Amphiphysin/Rvs; BLASTp: Basic local alignment search tools protein; CFW: Calcofluor white; CM: Complete media; CR: Congo red; DEP-DOMAIN: Dishevelled, egl-10 and pleckstrin domain; DTT: Dithiothreitol; EDTA: Ethylenediaminetetraacetic acid; EndoA: Endophilin-A; F-BAR: Fes/CIP4 (Cdc42-interacting protein 4) with BAR domain; GFP: Green fluorescent protein; GRAF1: GTPase regulator associated 
with focal adhesion kinase-1; Gvp36: Golgi vesicle protein of $36 \mathrm{kDa}$; HPH: Hygromycin phosphotransferase; I-BAR: Inverse Bin/Amphiphysin/Rvs domain family; KEGG: Kyoto Encyclopedia of Genes and Genomes; MoBARA: M. oryzae Bin/Amphiphysin/Rvs-A; MoBAR-B: M. oryzae Bin/Amphiphysin/ Rvs-B; MocMAPK-A: M. oryzae cyclic adenosine monophosphate-dependent protein kinase-A; MoCON7: M. oryzae conidiation-related gene CON7; MoMAC1: M. oryzae membrane-bound adenylate cyclase1; MoMSB2: M. oryzae (signaling mucin) multicopy suppressor of bud emergence 2; MoOSBP-1: M. oryzae oxysterol binding protein-1; MoOSBP-2: M. oryzae oxysterol-binding protein-2; MoOSBP-4: M. oryzae oxysterol-binding protein4; MoPMK1: M. oryzae mitogen activated protein kinase1; MoSED5: M. oryzae integral membrane protein sed5; MOSEP3 and MOSEP5: M. oryzae septin proteins3 and 5; MoVTI1: M. oryzae vesicle transport V-SNARE; NaCl: Sodium chloride; N-BAR-DOMAIN: N-terminal amphipathic helix domain; ORF: Open reading frame; PCR: Polymerase chain reaction; PH-DOMAIN: Pleckstrin Homology domain; PX-DOMAIN: Phox domain (phosphoinositide-binding structural domain); qPCR: Quantitative polymerase chain reaction; RhoGAPDOMAIN: Ras homologous GTPase activating proteins domain; RhoGEFDOMAIN: Ras homologous Guanine nucleotide exchange factor; SDS: Sodium dodecyl sulphate; SDS-CTAB: Sodium dodecyl sulphate-cetyl trimethyl ammonium bromide; SH3-DOMAIN: Sarcoma homology 3 domain; TE buffer: Tris-ethylenediaminetetraacetic acid buffer; VASt-DOMAIN: Vascular associated death1 analog of star-related lipid transfer domain; WASP: Wiskott-Aldrich syndrome protein

\section{Acknowledgments}

Not applicable.

\section{Authors' contributions}

$\mathrm{JN}, \mathrm{ZW}$ and $\mathrm{LL}$ conceived the work, designed the experiments and wrote the manuscript. LL, XiC, AS, SC and XuC conducted phenotype analysis and microscope examination. All authors read and approved the final manuscript.

\section{Funding}

This study was supported with funding from Fujian Provincial Natural Science Foundation for JN (Grant No: 2019 J01384).

\section{Availability of data and materials}

Materials, as well as research results (data) presented and discussed in this study are available and could be obtained from the authors.

\section{Ethics approval and consent to participate}

Not Applicable.

\section{Consent for publication}

Not Applicable.

\section{Competing interests}

The authors declare that they have no competing interests.

\section{Author details}

${ }^{1}$ State Key Laboratory for Ecological Pest Control of Fujian and Taiwan Crops, College of Life Science, Fujian Agriculture and Forestry University, Fuzhou 350002 , China. ${ }^{2}$ Institute of Oceanography, Minjiang University, Fuzhou 350108, China

Received: 15 May 2019 Accepted: 9 October 2019 Published online: 04 November 2019

\section{References}

Abdul W, Aliyu SR, Lin L, Sekete M, Chen X, Otieno FJ, et al. Family-four aldehyde dehydrogenases play an indispensable role in the pathogenesis of Magnaporthe oryzae. Front Plant Sci. 2018;9:980.

Aliyu SR, Lin L, Chen X, Abdul W, Lin Y, Otieno FJ, et al. Disruption of putative short-chain acyl-CoA dehydrogenases compromised free radical scavenging, conidiogenesis, and pathogenesis of Magnaporthe oryzae. Fungal Genet Biol. 2019;127:23-34

Anggono V, Robinson PJ. Dynamin. In: Squire LR, editor. Encyclopedia of neuroscience. Oxford: Academic; 2009. p. 725-35.

Baluška F, Levin M. On having no head: cognition throughout biological systems. Front Psychol. 2016;7:902.
Carlier MF, Pernier J, Montaville P, Shekhar S, Kühn S. Control of polarized assembly of actin filaments in cell motility. Cell Mol Life Sci. 2015;72:3051-67.

Chen J, Zheng W, Zheng S, Zhang D, Sang W, Chen X, et al. Rac1 is required for pathogenicity and Chm1-dependent conidiogenesis in rice fungal pathogen Magnaporthe grisea. PLoS Pathog. 2008;4:e1000202.

Chi RJ, Harrison MS, Burd CG. Biogenesis of endosome-derived transport carriers. Cell Mol Life Sci. 2015;72:3441-55.

Dagdas YF, Yoshino K, Dagdas G, Ryder LS, Bielska E, Steinberg G, et al. Septinmediated plant cell invasion by the rice blast fungus, Magnaporthe oryzae. Science. 2012;336:1590-5.

Douglas LM, Martin SW, Konopka JB. BAR domain proteins Rvs161 and Rvs167 contribute to Candida albicans endocytosis, morphogenesis, and virulence. Infect Immun. 2009;77:4150-60.

Flynn KC. The cytoskeleton and neurite initiation. BioArchitecture. 2013;3:86-109.

Franquelim HG, Khmelinskaia A, Sobczak JP, Dietz H, Schwille P. Membrane sculpting by curved DNA origami scaffolds. Nat Commun. 2018;9:811.

Garcia-Garcia T, Poncet S, Derouiche A, Shi L, Mijakovic I, Noirot-Gros MF. Role of protein phosphorylation in the regulation of cell cycle and DNA-related processes in bacteria. Front Microbiol. 2016;7:184.

Giovannetti M, Ayio L, Sbrana C, Citernesi AS. Factors affecting appressorium development in the vesicular-arbuscular mycorrhizal fungus Glomus mosseae (Nicol. \& Gerd.) Gerd. \& Trappe. New Phytol. 1993;123:115-22.

Gomez-Navarro N, Miller E. Protein sorting at the ER-Golgi interface. J Cell Biol. 2016;215:769-78

Goswami RS. Targeted gene replacement in fungi using a split-marker approach. In: Bolton M, Thomma BPHJ, editors. Plant fungal pathogens. Methods in molecular biology (methods and protocols), vol. 835. Totowa: Humana Press; 2012. p. 255-69.

Grassart A, Cheng AT, Hong SH, Zhang F, Zenzer N, Feng Y, et al. Actin and dynamin2 dynamics and interplay during clathrin-mediated endocytosis. J Cell Biol. 2014;205:721-35.

Hanks SK, Hunter T. Protein kinases 6 . The eukaryotic protein kinase superfamily: kinase (catalytic) domain structure and classification. FASEB J. 1995;9:576-96.

Inadome H, Noda Y, Adachi H, Yoda K. Immunoisolaton of the yeast Golgi subcompartments and characterization of a novel membrane protein, Svp26, discovered in the Sed5-containing compartments. Mol Cell Biol. 2005;25: 7696-710.

Kessels MM, Qualmann B. Different functional modes of BAR domain proteins in formation and plasticity of mammalian postsynapses. J Cell Sci. 2015;128: 3177-85.

Kong LA, Li GT, Liu Y, Liu MG, Zhang SJ, Yang J, et al. Differences between appressoria formed by germ tubes and appressorium-like structures developed by hyphal tips in Magnaporthe oryzae. Fungal Genet Biol. 2013;56: 33-41.

Lanzetti L. Actin in membrane trafficking. Curr Opin Cell Biol. 2007;19:453-8.

Liu S, Xiong X, Zhao X, Yang X, Wang H. F-BAR family proteins, emerging regulators for cell membrane dynamic changes-from structure to human diseases. J Hematol Oncol. 2015;8:47.

Liu W, Zhou X, Li G, Li L, Kong L, Wang C, et al. Multiple plant surface signals are sensed by different mechanisms in the rice blast fungus for appressorium formation. PLoS Pathog. 2011:7:e1001261.

Livak KJ, Schmittgen TD. Analysis of relative gene expression data using real-time quantitative $P C R$ and the $2-\Delta \Delta C T$ method. Methods. 2001;25:402-8.

Lodish H, Berk A, Kaiser CA, Krieger M, Scott MP, Bretscher A, et al. Molecular cell biology. 6th ed. New York: WH Freeman \& Co; 2008.

Mcdermott H, Kim K. Molecular dynamics at the endocytic portal and regulations of endocytic and recycling traffics. Eur J Cell Biol. 2015;94:235-48.

Meinecke M, Boucrot E, Camdere G, Hon WC, Mittal R, Mcmahon HT. Cooperative recruitment of dynamin and BIN/amphiphysin/Rvs (BAR) domain-containing proteins leads to GTP-dependent membrane scission. J Biol Chem. 2013;288:6651-61.

Meng S, Torto-Alalibo T, Chibucos MC, Tyler BM, Dean RA. Common processes in pathogenesis by fungal and oomycete plant pathogens, described with gene ontology terms. BMC Microbiol. 2009;9:S7.

Mim C, Unger VM. Membrane curvature and its generation by BAR proteins. Trends Biochem Sci. 2012;37:526-33.

Noguchi H. Membrane tubule formation by banana-shaped proteins with or without transient network structure. Sci Rep. 2016;6:20935.

Norvienyeku J, Zhong Z, Lin L, Dang X, Chen M, Lin X, et al. Methylmalonatesemialdehyde dehydrogenase mediated metabolite homeostasis essentially regulate conidiation, polarized germination and pathogenesis in Magnaporthe oryzae. Environ Microbiol. 2017;19:4256-77. 
Olivera-Couto A, Graña M, Harispe L, Aguilar PS. The eisosome core is composed of BAR domain proteins. Mol Biol Cell. 2011;22:2360-72.

Paez Valencia J, Goodman K, Otegui MS. Endocytosis and endosomal trafficking in plants. Annu Rev Plant Biol. 2016:67:309-35.

Peter BJ, Kent HM, Mills IG, Vallis Y, Butler PJG, Evans PR, et al. BAR domains as sensors of membrane curvature: the amphiphysin BAR structure. Science. 2004;303:495-9.

Pollard TD, Earnshaw WC, Lippincott-Schwartz J, Johnson G. Cell biology (3rd ed). Philadelphia: Elsevier Health Sciences; 2016

Richter S, Kientz M, Brumm S, Nielsen ME, Park M, Gavidia R, et al. Delivery of endocytosed proteins to the cell-division plane requires change of pathway from recycling to secretion. Elife. 2014;3:e02131.

Ryder LS, Talbot NJ. Regulation of appressorium development in pathogenic fungi. Curr Opin Plant Biol. 2015;26:8-13.

Saarikangas J, Zhao H, Lappalainen P. Regulation of the actin cytoskeleton-plasma membrane interplay by phosphoinositides. Physiol Rev. 2010;90:259-89.

Salzer U, Kostan J, Djinović-Carugo K. Deciphering the BAR code of membrane modulators. Cell Mol Life Sci. 2017;74:2413-38.

Samalova M, Mélida H, Vilaplana F, Bulone V, Soanes DM, Talbot NJ, et al. The $\beta$ 1,3-glucanosyltransferases (Gels) affect the structure of the rice blast fungal cell wall during appressorium-mediated plant infection. Cell Microbiol. 2017; 19:e12659.

Simunovic M, Voth GA, Callan-Jones A, Bassereau P. When physics takes over: BAR proteins and membrane curvature. Trends Cell Biol. 2015;25:780-92.

Soykan T, Kaempf N, Sakaba T, Vollweiter D, Goerdeler F, Puchkov D, et al. Synaptic vesicle endocytosis occurs on multiple timescales and is mediated by formin-dependent actin assembly. Neuron. 2017;93:854-66.

Stanishneva-Konovalova TB, Derkacheva NI, Polevova SV, Sokolova OS. The role of BAR domain proteins in the regulation of membrane dynamics. Acta Nat. 2016;8:60-9.

Suetsugu S. Higher-order assemblies of BAR domain proteins for shaping membranes. Microscopy. 2016;65:201-10.

Sun J. Characterization of regulatory factors controlling tip growth in Nicotiana tabacum pollen tubes. PhD thesis. Uppsala: Swedish University of Agricultural Sciences; 2015. https://pub.epsilon.slu.se/12822/49/sun_j_151124.pdf

Vergés M. Retromer in polarized protein transport. Int Rev Cell Mol Biol. 2016;323: 129-79.

Williams M, Kim K. From membranes to organelles: emerging roles for dynaminlike proteins in diverse cellular processes. Eur J Cell Biol. 2014;93:267-77.

Xu JR, Hamer JE. MAP kinase and CAMP signaling regulate infection structure formation and pathogenic growth in the rice blast fungus Magnaporthe grisea. Genes Dev. 1996;10:2696-706.

Zhang X, Wang G, Yang C, Huang J, Chen X, Zhou J, et al. A HOPS protein, MoVps41, is crucially important for vacuolar morphogenesis, vegetative growth, reproduction and virulence in Magnaporthe oryzae. Front Plant Sci. 2017;8:1091.

Ready to submit your research? Choose BMC and benefit from:

- fast, convenient online submission

- thorough peer review by experienced researchers in your field

- rapid publication on acceptance

- support for research data, including large and complex data types

- gold Open Access which fosters wider collaboration and increased citations

- maximum visibility for your research: over $100 \mathrm{M}$ website views per year

At $\mathrm{BMC}$, research is always in progress.

Learn more biomedcentral.com/submissions 